Research Article

\title{
Zika Virus: An Emerging Mosquito-Borne Disease Threat in Kerala
}

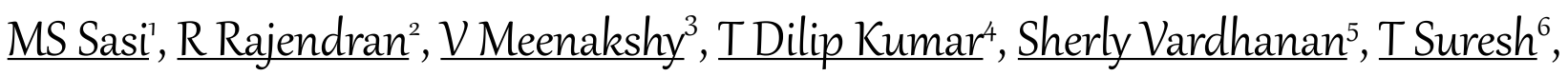 \\ $\mathrm{KRegu}^{7}, \underline{\mathrm{SN} \mathrm{Sharma}}^{8}$
}

${ }^{1}$ Assistant Director (Entomology), Directorate of Health Services, Thiruvananthapuram, Government of Kerala, India.

${ }^{2}$ Consultant, ${ }^{7}$ Additional Director and Head, National Centre for Disease Control, Calicut, Kerala, India.

${ }^{3}$ Director of Health Services (I/C) and SPO (NVBDCP), Directorate of Health Services, Thiruvananthapuram, Government of Kerala, India.

${ }^{4}$ Filaria Consultant, Regional Office for Health and Family Welfare, Thiruvananthapuram, Kerala, India.

${ }^{5}$ District Vector Borne Disease Control Officer, District Medical Office (H), Thiruvananthapuram, Kerala, India.

${ }_{6}^{6}$ Former District Vector Borne Disease Control Officer, Health Services Department, Kerala, India.

${ }^{8}$ Consultant, National Centre for Disease Control, 22-Sham Nath Marg, Delhi, India.

DOI: https://doi.org/10.24321/0019.5138.202158

\section{I $\quad \mathbf{N} \quad \mathbf{F} \quad \mathbf{O}$}

\section{Corresponding Author:}

MS Sasi, Directorate of Health Services,

Government of Kerala, India.

E-mail Id:

adentomology@gmail.com

Orcid Id:

https://orcid.org/0000-0002-2839-9768

How to cite this article:

Sasi MS, Rajendran R, Meenakshy V, Dilip Kumar T, Vardhanan S, Suresh T, Regu K, Sharma SN. Zika Virus: An Emerging Mosquito-Borne Disease Threat in Kerala. J Commun Dis. 2021;53(3):201212.

Date of Submission: 2021-08-06

Date of Acceptance: 2021-09-06

\section{$\begin{array}{llllllll}\mathbf{A} & \mathbf{B} & \mathbf{S} & \mathbf{T} & \mathbf{R} & \mathbf{A} & \mathbf{C} & \mathbf{T}\end{array}$}

First laboratory confirmed Zika case in Kerala was reported in Thiruvananthapuram, on 8th July 2021. Since then, 68 ZIKV positive cases have been reported from Kerala, with majority of cases from Thiruvananthapuram Corporation area. Based on the preliminary investigation, micro containment zones were identified and detailed investigation was carried out in these areas. Entomological surveillance indicated that all the three species of Aedes mosquitoes - Ae. aegypti, Ae. albopictus and $A e$. vittatus were present in the survey areas. The Aedes larval indices were found above the critical level. The most preferred habitats of Aedes mosquitoes were water stagnated areas in cemented floor of the newly constructing buildings followed by cement tanks/ cement pits and discarded tires. ZIKV could be detected from all the three Aedes mosquitoes collected from the micro containment zones. Trasovarial transmission of ZIKV could be noted in this outbreak. Vector control was intensified with the active participation of local bodies and local health institutions. The epidemiological study showed most of the Zika positive cases has fever, rash and conjunctivitis and in majority of cases, the duration of the illness lasts only for 2-3 days. The females were more affected. The most affected age group was 21-30 followed by $31-40$. Among the 68 ZIKV positive cases, 7 (10.29\%) were pregnant women. No major anomaly was detected in ZIKV positive cases; however there is a need to scale up surveillance and vector control activities to prevent further outbreaks in Kerala and elsewhere.

Keywords: Zika Virus, Kerala, Aedes vittatus, Breeding Preference Ratio 


\section{Introduction}

Zika virus (ZIKV) is an emerging arbovirus transmitted by Aedes (Stegomyia) mosquitoes. The virus belongs to the genus Flavivirus, family Flaviviridae, and is closely related to human pathogenic viruses such as Dengue, Chikungunya, Yellow fever, Japanese encephalitis and West Nile viruses. The virus was first identified in a rhesus monkey in the tropical Zika forest located in Entebbe town in Uganda in April 1947 during the surveillance of Yellow fever virus (YFV) and hence the name Zika virus. ${ }^{1}$ In January 1948, about 10 months after ZIKV detection from rhesus monkey, the virus was isolated from Aedes africanus mosquito from the same Zika forest. ${ }^{2}$ The first evidence of the presence of ZIKV in a human being was described in 1952. In this study, eight viruses such as Mengo virus, Bwamba fever, Nataya, West Nile and Zika virus were isolated from human sera. ZIKV antibodies were neutralized in approximately 38 out of 297 specimen tested. ${ }^{3}$ The isolation of ZIKV from the serum of individuals was also incidental and was similar to the isolation of this virus from rhesus monkey in 1947. Hence, this observation cannot be considered a true outbreak, occurrence or exemplification of the disease itself.

The first confirmed case of ZIKV with probable disease manifestation was described in 1954 during an investigation of a jaundice outbreak believed to be caused by Yellow fever (YF) in Eastern Nigeria. During this outbreak there were three patients observed in outpatient setting. Of these three cases, the first two were Nigerian men aged 30 and 24 years old and the third case was a 10 year old African girl. The 30 year old Nigerian patient presented with cough, joint pain and fever and mild jaundice and the 24 year old patient showed similar symptoms and had pain behind his eyes and loose watery stool but were not jaundiced. In both these individuals no malarial parasites could be detected in the blood. However in the 10 year old girl who presented with fever and headaches and did not show the signs of jaundice. However her blood did contain numerous malarial parasites. ZIKV was isolated for the first time from this 10 year old African girl. ${ }^{4}$

ZIKV was sporadically isolated in numerous African countries during 1964-1970, which clearly demonstrated the vast geographical dissemination of this virus. ${ }^{5} \mathrm{~A}$ special ZIKV study was carried out during 1970-1975 in Oyo State, which is located in Southwestern Nigeria. In this study, two ZIKV isolations - young children aged 2 and 10 years of old, were made from 10,778 blood samples.

The first documented ZIKV outbreak occurred in 2007 in Yap Island in the Federated States of Micronesia. ${ }^{6,7}$ This was the first major outbreak detected outside Africa and Asia. ${ }^{8}$, ${ }^{9}$ This outbreak was followed by outbreaks of ZIKV in French Polynesia during 2013-2014..$^{10}$ In 2008, a man who was infected with ZIKV in Senegal returned to the United States. He had sexual intercourse with his wife who subsequently developed ZIKV disease which was confirmed by serological test. His semen, however, could not test for the presence of ZIKV. But during the 2013 ZIKV outbreak, ZIKV was detected in the semen of a 44 year old man in Tahiti by real-time reverse transcriptase test. This would be the first confirmed detection of ZIKV in semen with the potential for sexual transmission. ${ }^{11}$ In early 2015, there were reports of patients presenting with Dengue-like illness in the eastern part of Brazil. ${ }^{12}$ During this fever outbreak, samples from 21 patients were tested for DENV and CHIKV and came out negative. The investigators tested 2 out of 21 samples against ZIKV and were found positive, specifically the Asian lineage. This was the first confirmed ZIKV infection in Brazil. From December 2014 to January 2016, ZIKV disease had spread to entire Brazil including North, Northeast, Central-west, Southeast and South. ${ }^{13}$ In August 2014, World Sprints Championship Canoe race was held in Rio De Janeiro, Brazil, where four Pacific countries participated in the completion (French Polynesia, New Caledonia, Cook Island and Easter Island). All these countries had ZIKV disease outbreak in 2014. ${ }^{14}$ This could have been the potential transmission route for the entry and spread of ZIKV in South American countries.

The first case of Zika was detected in November 2016in India by the Virus Research Diagnostic Laboratory at Ahmadabad, India and subsequently confirmed by National Institute of Virology, Pune. Three more ZIKV confirmed cases- 34 year old female, 64 year old male and 22 year old pregnant female of 37 weeks gestation were reported from Ahmadabad. ${ }^{15}$ In July 2017, a 28 year old tailor, a resident of Nataranpalayam Panchayath of Krishnagiri district of Tamil Nadu reported to the Anchetty PHC with complaints of fever, redness in the eye, skin rashes and joint pain. His sample tested have been found positive for ZIKV and was confirmed by NIV, Pune and this is the first laboratory confirmed ZIKV in Tamil Nadu. ZIKV outbreak was reported in Jaipur, Rajasthan during September-October 2018 and in Madhya Pradesh during October-November 2018. During the Zika outbreaks in Rajasthan and Madhya Pradesh, a total of 159 and 127 ZIKV positive cases with 63 and 42 infected pregnant women were detected respectively. ${ }^{16}$

During the first ZIKV outbreak in Kerala (July-August 2021), a total of 68 confirmed cases including 7 pregnant women were reported as on 26-8-2021. A 50 year old woman from Belsar village of Pune district tested positive for ZIKV infection on 30th July 2021. The woman was also found positive for Chikungunya. This is the first ZIKV confirmed case in Maharashtra. Of the total 187 blood samples tested, 7 patients were found positive for dengue, 86 with Chikungunya and one patient with ZIKV. Present observation relates to the investigation carried out in Thiruvananthapuram during the outbreak of ZIKV infection. Attempts have been made to study the ecology of the disease vectors, vector incrimination, epidemiology of ZIKV infection and disease prevention strategy. 


\section{Materials and Methods}

\section{Study Area}

Most of the initial ZIKV cases including the first laboratory confirmed case reported in Thiruvananthapuram, Kerala state are related to in and around a multi-specialty private hospital located in city limits. The city corporation is spread over $214.86 \mathrm{~km}^{2}$ and consists of 100 wards. The total population of city corporation is $9,57,730$ inhabitants. Thiruvananthapuram district gets an average of $1835 \mathrm{~mm}$ of rainfall per year or $152.9 \mathrm{~mm}$ per month. Usually, there are 132 days/year with more than $0.1 \mathrm{~mm}$ of rainfall or 11 days with a quantity of rain, sleet, snow, etc. per month. The actual rainfall in Thiruvananthapuram district from 1st June to 20th August was $409.8 \mathrm{~mm}$ during which ZIKV outbreak reported in the district. The preliminary investigation evidenced that the epicenter of the first outbreak of ZIKV in Kerala is connected with the private hospital premise located in 95th Division/Anamugham.

As new cases have been started reporting since 8th July 2021, it has been planned to carry out a detailed investigation covering the epidemiology, entomology, vector incrimination and disease prevention strategy.

\section{Entomological Investigation}

The entomological investigation was carried out within a $3 \mathrm{~km}$ radius of the Multi-specialty private hospital premise where $32 \%$ of the cases reported including the first confirmed ZIKV case. On the basis of confirmed daily Zika cases reported by the State Health Authorities (SHAs), Entomological surveillance was done by the State Entomology Team (SET) in 14 divisions of Thiruvananthapuram corporation area (Map 1). The residential, commercial premises and public places were randomly selected to assess vector breeding habitats. All the accessible water holding containers/habitats in and around the house/ premise were checked for the presence of immature stages of mosquitoes and recorded. Larvae/ pupae from each container were collected separately. The immature stages of mosquitoes from small containers (less than 10 Liter capacity) were collected using appropriate Steiner. Larvae/ pupae were collected from large containers using modified larval dipper. The larvae/pupae collected from each container/source were kept in separate vials labeled with date of collection, name of the locality. House number and breeding source (container type/ habitat). The immature kept in separate vials were placed in rearing jars filled with $150 \mathrm{~mL}$ freshwater and were covered with fine piece of mosquito net. All larvae were provided with larval food (prepared by mixing $12.5 \mathrm{~g}$ of tuna meal, $3.5 \mathrm{~g}$ of yeast and $9.0 \mathrm{~g}$ of bovine liver powder, in $100 \mathrm{~mL}$ of distilled water). Larvae and pupae were identified until the emergence of adults and the mosquitoes were identified using standard key (WHO, 2020).

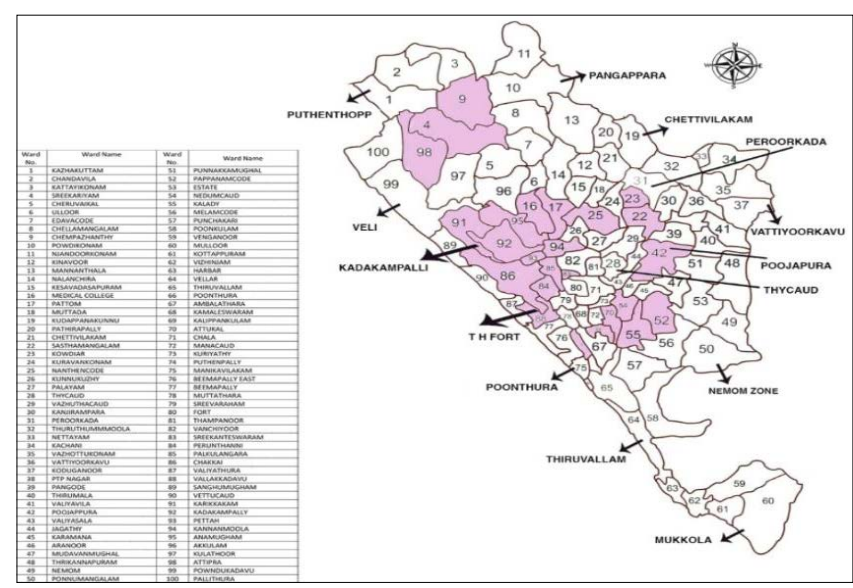

Map I.Zika Fever Containment Zones in Trivandrum Municipal Corporation Area

House/Premise index (HI/PI), Container index (CI), Breteau index $(\mathrm{BI})$, and the Breeding Preference Ratio (BPR) of vector mosquitoes were analyzed.

\section{Detection of ZIKV from Mosquitoes}

The field collected adult mosquitoes/adult mosquitoes reared from immature were identified. The identified male and female mosquitoes kept in separate pools. The mosquitoes in different pools with details such as place of collection, male/ female mosquito species, Number of mosquitoes in each pool, etc. were sent to NIV, Field unit at Alappuzha and Rajiv Gandhi Centre for Biotechnology, Thiruvananthapuram for virus detection using RT-PCR/virus isolation protocols.

\section{Epidemiological Investigation}

Outbreak investigation was carried out in $3 \mathrm{Km}$ radius of the premise where a cluster of ZIKV positive cases reported including the first laboratory confirmed case in Thiruvananthapuram, Kerala state. Fever survey was done among patient contacts, other febrile cases and pregnant women in micro containment Zones. Surveillance was enhanced to include samples from other districts such as Kollam, Kottayam and Ernakulam. Presence of ZIKV in serum samples were detected by real time PCR test, singleplex test and CDC trioplex kit. The area and day-wise ZIKV positive cases reported in Thiruvananthapuram and elsewhere, the age and gender profile of ZIKV positive cases, clinical manifestations, and co-morbidity associated with Zika positive cases, occupation of Zika confirmed cases. An attempt was also made to find out the relationship of ZIKV positive cases and blood group of infected individuals during the present disease outbreak.

\section{Results}

\section{Entomological Surveillance}

Entomological study was done in 14 divisions of Thiruvananthapuram Corporation (urban) area including 
9 micro containment divisions. The divisions are Karikkakam (D. No. 91), Kadakamppally (92), Pettah (93), Kannanmoola (94), Anamugham (95), Akkulam (96), Pattom (17), Kunnukuzhi (26) and Medical College Division (16). The native place of first confirmed ZIKV case is in Pazhukal in Kanyakumari district, Tamil Nadu (Kerala-Tamil Nadu border area) and presently she is residing in Parassala (Kerala). Hence the team carried out vector surveillance in both these areas. In addition to this, the survey was done in public places such as Primary/ Family health centers, Zoo, etc. (Table 1).

A total of 675 houses/premises were searched for Aedes breeding in ZIKV affected areas of Thiruvananthapuram district from 8th to 26th July 2021. Aedes breeding was noted in 183 houses/premises (HI/PI- 27.1\%). Of the total 1,229 water holding containers/sources searched, 387 containers were found positive for Aedes larvae ( $\mathrm{Cl}-31.5 \%)$. In order to find out a relation between positive containers and number of houses examined for larval presence, the Breteau index (BI) was calculated as 57.3. The Aedes larval indices were found above the critical level in all the localities surveyed (Table 1). The Breteau index (BI) was very high (176.9) in a multispecialty private hospital premises such as hospital parking areas, construction site on the 8th floor and yards $1 \& 2$. Similarly a very BI (257.1) could be noted in a flat and associated buildings seen in the immediate surroundings of multy specialty private hospital such as Heera Developers (14 floors), SM Residency (10 floors), SRK poultry farm, shops and houses (Table 1).

Table I.Aedes Larval Indices in Zika Affected Areas in Thiruvananthapuram Corporation Area

\begin{tabular}{|c|c|c|c|c|c|c|c|}
\hline $\begin{array}{l}\text { Localities/Divisions } \\
\text { searched }\end{array}$ & $\begin{array}{c}\text { Houses/ } \\
\text { premises visited }\end{array}$ & $\begin{array}{c}\text { Houses/ } \\
\text { premises positive }\end{array}$ & $\begin{array}{l}\text { Containers } \\
\text { searched }\end{array}$ & $\begin{array}{l}\text { Containers } \\
\text { positive }\end{array}$ & $\begin{array}{l}\mathrm{HI} \\
(\%)\end{array}$ & $\begin{array}{c}\mathrm{Cl} \\
(\%)\end{array}$ & BI \\
\hline Nanthancode / 25 & 63 & 14 & 28 & 16 & 22.2 & 57.1 & 25.4 \\
\hline $\begin{array}{c}\text { Multispecialty Private } \\
\text { Hospital } \\
\text { Anamugham/95 }\end{array}$ & 13 & 5 & 57 & 23 & 38.4 & 40.4 & 176.9 \\
\hline $\begin{array}{c}\text { Multispecialty Private } \\
\text { Hospital premises } \\
\text { Anamugham/95 }\end{array}$ & 56 & 51 & 171 & 144 & 91.1 & 84.2 & 257.1 \\
\hline $\begin{array}{l}\text { Multispecialty } \\
\text { Private Hospital } \\
\text { surroundings } \\
\text { Anamugham/95 }\end{array}$ & 33 & 8 & 75 & 20 & 24.2 & 26.7 & 60.6 \\
\hline $\begin{array}{c}\text { Venpalavattom } \\
\text { Kadakamppally/92 }\end{array}$ & 30 & 5 & 42 & 11 & 16.7 & 26.2 & 36.7 \\
\hline $\begin{array}{c}\text { Family Health Centre } \\
\text { Kadakamppally/92 }\end{array}$ & 6 & 2 & 7 & 3 & 33.3 & 42.9 & 50.0 \\
\hline Kunnukuzhi/17 & 40 & 13 & 67 & 20 & 32.5 & 29.9 & 50.0 \\
\hline $\begin{array}{l}\text { Palkulangara } \\
\text { Pettah/93 }\end{array}$ & 24 & 3 & 34 & 5 & 12.5 & 14.7 & 20.8 \\
\hline Karikkakom/91 & 50 & 16 & 108 & 19 & 32.0 & 17.6 & 38.0 \\
\hline $\begin{array}{c}\text { Tagore Garden } \\
\text { Medical College/16 }\end{array}$ & 67 & 9 & 37 & 13 & 13.4 & 35.1 & 19.4 \\
\hline Akkulam/96 & 31 & 5 & 128 & 9 & 16.1 & 7.0 & 29.0 \\
\hline Pattom/17 & 57 & 8 & 115 & 16 & 14.0 & 13.9 & 28.1 \\
\hline $\begin{array}{c}\text { Kannanmoola } \\
\text { Kumarapuram/16 }\end{array}$ & 30 & 7 & 71 & 19 & 23.3 & 26.8 & 63.3 \\
\hline Balaramapuram/19 & 30 & 4 & 72 & 8 & 13.3 & 11.1 & 26.6 \\
\hline Pangappara/04 & 30 & 17 & 112 & 33 & 56.7 & 29.5 & 110.0 \\
\hline $\begin{array}{c}\text { Kannanthura coastal } \\
\text { area }\end{array}$ & 32 & 4 & 38 & 4 & 12.5 & 10.5 & 12.5 \\
\hline
\end{tabular}




\begin{tabular}{|c|c|c|c|c|c|c|c|}
\hline $\begin{array}{c}\text { Zoo, } \\
\text { Thiruvananthapuram }\end{array}$ & 8 & 4 & 25 & 11 & 50.0 & 44.0 & 137.5 \\
\hline $\begin{array}{c}\text { Parassala } \\
\text { Cheruvarakkonam \& } \\
\text { Thalachanvila }\end{array}$ & 75 & 8 & 42 & 13 & 10.7 & 31.0 & 17.3 \\
\hline
\end{tabular}

Table 2.Breeding Preference Ratio (BPR) of Aedes Mosquitoes in Zika Affected Areas of Thiruvananthapuram Corporation Area

\begin{tabular}{|c|c|c|c|c|}
\hline S. No. & Breeding habitats & Examined (\%) & Positive (\%) & Breeding Preference Ratio (BPR) \\
\hline 1. & $\begin{array}{c}\text { Plastic containers } \\
\text { (broken trays, buckets, cups, } \\
\text { chairs, etc.) }\end{array}$ & $141(13.26)$ & $36(9.94)$ & 0.75 \\
\hline 2. & $\begin{array}{l}\text { Plant pot trays } \\
\text { (Plastic) }\end{array}$ & $148(13.92)$ & $36(9.94)$ & 0.71 \\
\hline 3. & Tarpaulin sheets & $37(3.48)$ & $17(4.70)$ & 1.35 \\
\hline 4. & $\begin{array}{c}\text { Metal containers } \\
\text { (Paint tin, steel \& aluminum } \\
\text { utensils) }\end{array}$ & $62(5.83)$ & $11(3.03)$ & 0.52 \\
\hline 5. & Glass bottles & $147(13.82)$ & $17(4.70)$ & 0.34 \\
\hline 6. & Money plant pots (Glass) & $84(7.90)$ & $22(6.08)$ & 0.77 \\
\hline 7. & Discarded tires & $73(6.87)$ & $34(9.39)$ & 1.37 \\
\hline 8. & $\begin{array}{l}\text { Water stagnated areas in } \\
\text { cemented floor of old/newly } \\
\text { constructing buildings }\end{array}$ & $164(15.43)$ & $139(38.40)$ & 2.49 \\
\hline 9. & Coconut shells & $42(3.95)$ & $6(1.66)$ & 0.42 \\
\hline 10. & Drums/barrels/synthetic tanks & $38(3.57)$ & $13(3.59)$ & 1.01 \\
\hline 11. & Earthen & $57(5.36)$ & $5(1.38)$ & 0.26 \\
\hline 12. & $\begin{array}{l}\text { Grinding stones/cement tanks/ } \\
\text { cement pits }\end{array}$ & $21(1.98)$ & $10(2.76)$ & 1.39 \\
\hline 13. & Tree holes & $25(2.35)$ & $11(3.04)$ & 1.29 \\
\hline 14. & $\begin{array}{c}\text { Junk materials (Damaged } \\
\text { wash basin/closets/flush tank/ } \\
\text { thermocol, etc.) }\end{array}$ & $24(2.26)$ & $5(1.38)$ & 0.61 \\
\hline & Total & 1,063 & 362 & \\
\hline
\end{tabular}

The position and nature of water holding containers seen scattered in the peridomestic environment may influence the site selection of Aedes mosquitoes for egg laying. A study has been done to find out the most preferred breeding sites of Aedes mosquitoes. The Breeding Preference Ratio (BPR) was found to be more (2.49) in water stagnated areas in cemented floor of the newly constructing buildings followed by grinding stones/cemented tanks/cemented pits (1.39), discarded tires (1.37), tarpaulin sheets (1.35), tree holes especially bamboo stumps (1.29), drums/barrels/ synthetic tanks (1.01), glass vases/pots kept for money plants (0.77), etc. (Table 2).

A team from DHS, Kerala visited Pazhukal, the native place of the first Zika virus positive case and searched for vector breeding habitats along with Tamil Nadu Entomology team. However due to intense source reduction activities done in that area, they could not locate any Aedes breeding sites in and around their residence. In the light of the first Zika virus case reported in a resident of Parassala and a native of Pazhukal, an area bordering Kerala and Tamil Nadu, The Directorate of Public Health (DPH) and Preventive Medicine, Tamil Nadu has taken up vector surveillance in the target area. 65 Aedes mosquito pools collected from this area were tested at the State Public Health Laboratory (SPHL), an ICMR approved RT-PCR laboratory. All pools were found negative for Zika virus. 


\section{Detection of ZIKV from Mosquitoes}

As a part of ZIKV outbreak investigation, the mosquitoes were collected from the disease affected areas in Thiruvananthapuram Corporation area on 10th and 11th July 2021. Both species of Aedes mosquitoes, Ae. aegypti and Ae. albopictus were collected from Nanthancode (Division No. 25) of Thiruvananthapuram Corporation. Among 10 Ae. aegypti pools, one pool (unfed female) was found positive for ZIKV infection by Real time PCR.

Ae. albopictus mosquitoes collected from Nanthancode were processed ( $n=57$, Male 15 \& female 42 ) in 21 pools. Four pools (3pools of unfed females and one pool with male mosquitoes) were found positive for ZIKV infection. In addition to this, three specimens of $A$ e. vittatus collected from Anayara, Thiruvananthapuram were processed. This pool of unfed specimens was also found positive for ZIKV infection. The Ae. aegypti mosquitoes collected from the multispecialty hospital premise Anamugham (Division No. 95) and Ae. vittatus mosquitoes collected from Nanthancode (Division No. 25) on 15th July 2021 were also found positive for ZIKV.

ZIKV could not be detected from Ae. aegypti and Ae. albopictus mosquitoes collected from Palkulangara (Division No. 85) and Kunnukuzhi (Division No. 26) and Kadakamppally (Division No. 92) of Thiruvananthapuram Corporation area.

\section{Epidemiological Investigation}

\section{Case History of the First Confirmed Zika Virus in Kerala}

Zika, a mosquito-borne viral infection, has been officially confirmed for the first time in Kerala on 8th July 2021. The virus was detected in the blood samples of a 24 year old pregnant woman, presently residing at Parassala of Thiruvananthapuram, Kerala state. She is a native of Pazhukal in Tamil Nadu. After her marriage, she was staying in her husband's house at Parassala. It is only $6 \mathrm{Km}$ away from her native place. She is working in a Service Cooperative Bank at Parassala. During the last three months she was staying in a rented house at Nanthancode, an area within Thiruvananthapuram Corporation limits for the convenience of consultation in a private hospital located in
Thiruvananthapuram city. She had regularly visited the same hospital for regular antenatal checkup. The woman, who had been in her final stage of gestation, got admitted for delivery at the hospital on 28th June 2021. She was suffering from fever, rashes and conjunctivitis. The woman was immediately referred from the Obstetrics and Gynecology Department to the Infectious Disease Department. There they tested for dengue and Chikungunya, two most prevalent mosquito-borne diseases in Kerala and elsewhere but both turned out negative. The blood sample was then sent to the Microbiology lab at Coimbatore, Tamil Nadu for Zika virus PCR test. Subsequently, the result came out confirming Zika virus. For confirmation, the sample was sent to the National Institute of Virology (NIV), Pune and confirmed as Zika positive on 8th July 2021. This is the first laboratory confirmed Zika virus case in Kerala. She has no travel history except her ups and down movement from her residence at Parassala to the working locality in nearby area. Meanwhile the woman gave birth to a child on 7 th July 2021 and the condition of mother and child is stable. Since the woman did not show any other complications, she recovered within six days.

\section{Transmission Dynamics of ZIKV in Kerala}

The confirmation of thirteen positive cases from a multispecialty private hospital in Thiruvananthapuram city and the confirmation of Zika case in a pregnant woman who was treated in the same hospital and occurrence of similar cases in the hospital prior to this is persuaded to believe that the recent Zika virus infection is some way connected to the hospital premise or the epicenter of infection is around the hospital. The first confirmed ZIKV case was reported on $8^{\text {th }}$ July 2021. Since then, regular surveillance was carried out in the entire district and information was given to other districts also to keep a vigil on ZIKV emergence.

During the Zika outbreak, a total of 679 samples were collected from the disease affected areas of the state and were sent to National Institute of Virology (NIV), ICMR, Alappuzha unit; Rajiv Gandhi Centre for Biotechnology (RGCB), Thiruvananthapuram; Public Health Laboratory, Thiruvananthapuram; and Government Medical College, Thiruvananthapuram for ZIKV confirmation (Table 3).

Table 3.Details of Samples Tested during Surveillance in ZIKV Affected

Districts as on 26-8-202I

\begin{tabular}{|c|c|c|c|c|c|c|c|c|}
\hline \multirow{2}{*}{ Cases } & \multicolumn{2}{|c|}{ Thiruvananthapuram } & \multicolumn{2}{c|}{ Kollam } & \multicolumn{2}{c|}{ Kottayam } & \multicolumn{2}{c|}{ Ernakulam } \\
\cline { 2 - 8 } & $\begin{array}{c}\text { Tested for } \\
\text { ZIKV }\end{array}$ & Positive (\%) & $\begin{array}{c}\text { Tested for } \\
\text { ZIKV }\end{array}$ & $\begin{array}{c}\text { Positive } \\
\text { (\%) }\end{array}$ & $\begin{array}{c}\text { Tested for } \\
\text { ZIKV }\end{array}$ & $\begin{array}{c}\text { Positive } \\
\text { (\%) }\end{array}$ & $\begin{array}{c}\text { Tested for } \\
\text { ZIKV }\end{array}$ & $\begin{array}{c}\text { Positive } \\
\text { (\%) }\end{array}$ \\
\hline $\begin{array}{c}\text { 8th July } \\
\text { 2021 to } \\
\text { 26th August } \\
\text { 2021 }\end{array}$ & 646 & $64(9.9 \%)$ & 07 & 01 & 05 & 01 & & \\
$(14.3 \%)$ & & & & & & & & 02 \\
$(20.0 \%)$ & 21 & \\
\hline
\end{tabular}




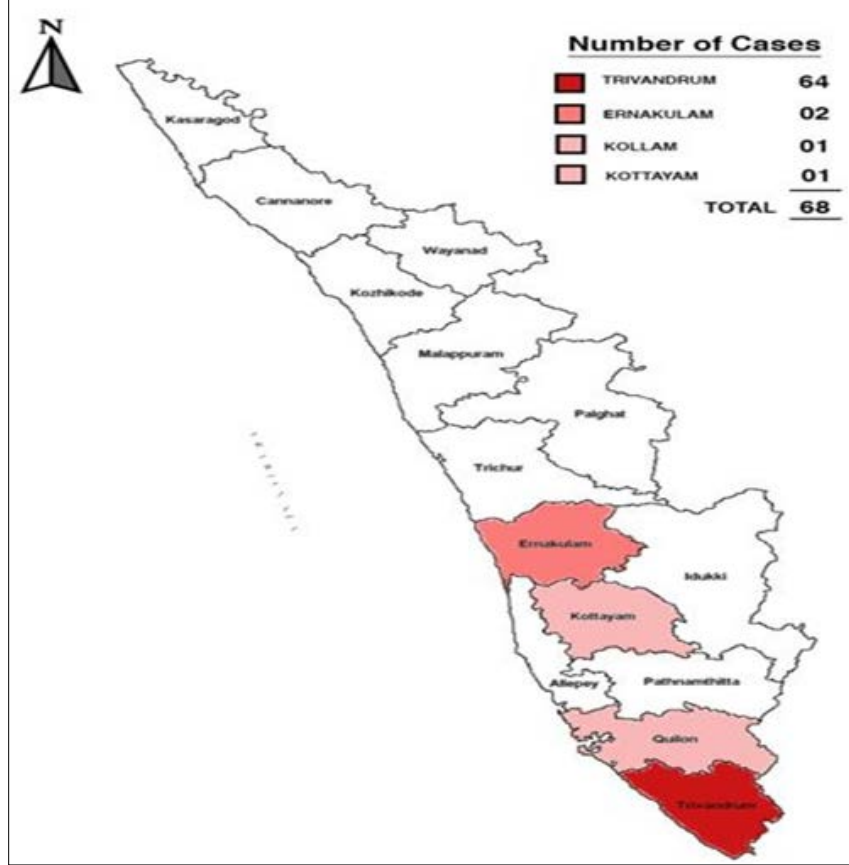

Figure I.Zika Fever Affected Districts in Kerala

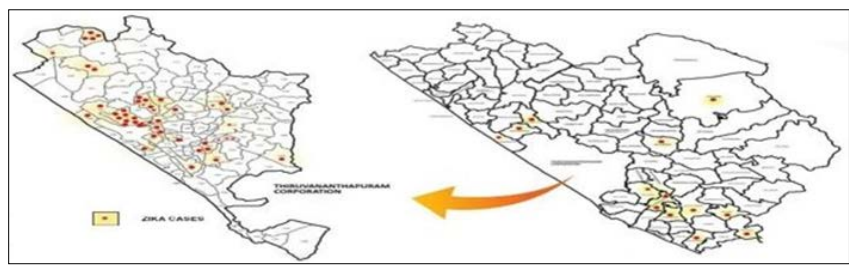

Figure 2.Spot Map of Zika Fever Cases in Trivandrum District Highlighting Cases in Corporation Area

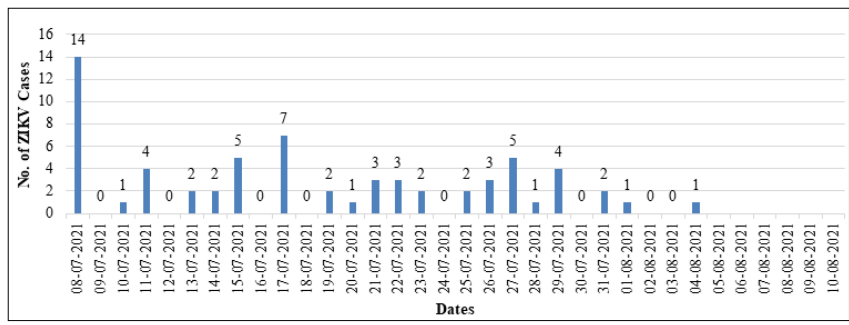

Figure 3.Day-wise Zika Virus Confirmed Cases Reported in Thiruvananthapuram, Kerala

From 8th July to 26th August 2021, a total of 68 Zika confirmed cases were reported from Kerala (Figure 1). Among these, 64 cases $(94.1 \%)$ are reported from Thiruvananthapuram district especially from Thiruvananthapuram Corporation area (Figure 2). Two ZIKV cases are reported from Ernakulam and one case each from Kollam and Kottayam districts. However, all the 4 cases are epidemiologically linked with Thiruvananthapuram outbreak. The day-wise ZIKV positive cases were recorded to find out the pattern of disease emergence (Figure 3).

\section{Clinical Manifestations Observed in ZIKV Confirmed Cases}

The signs and symptoms of 64 (95.5\%) ZIKV confirmed cases could be collected during the present outbreak. Most of the (86.5\%) ZIKV positive cases had mild signs and symptoms. Of the 64 cases, in 52 cases (81.25\%) the duration of illness lasts only for 2-3 days with an average 2.59 days. However, 5-7 days of duration was noted in $4.68 \%$ of Zika positive cases. Rash was found to be one of the significant clinical manifestation in $89 \%$ of ZIKV confirmed cases followed by fever $(78.1 \%)$, conjunctivitis $(51.6 \%)$, body pain $(50 \%)$ and joint pain (37.5\%) (Figure 4).

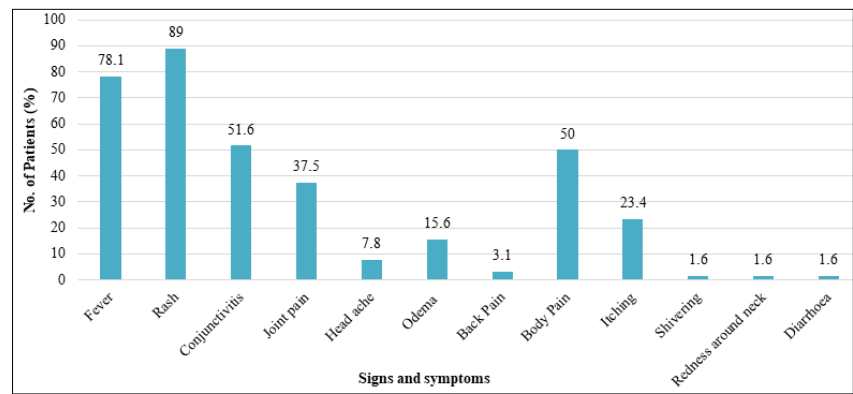

Figure 4.Clinical Manifestations Observed in ZIKV Positive Cases

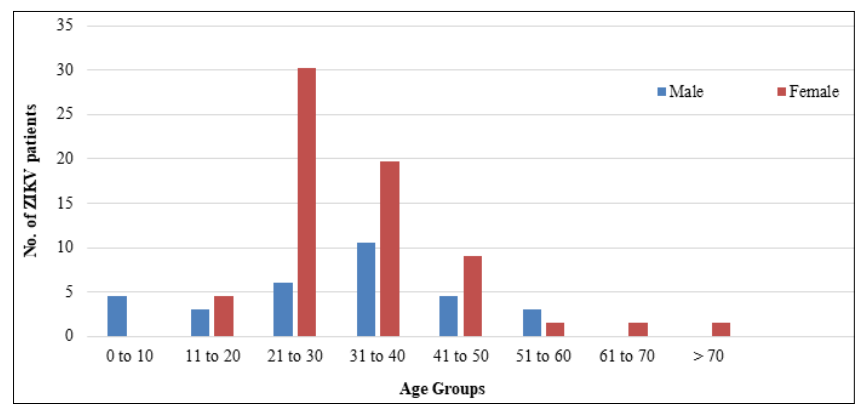

Figure 5.Age and Gender Profile of ZIKV Positive Cases

The co-morbidity associated with ZIKV noted in the present disease outbreak are thyroid illness (3.1\%) followed by $1.6 \%$ each with Parkinson syndrome, Autism, hypertension, fatty liver and diabetes. Unlike dengue, patients did not have retro-orbital pain, profound hypotension or signs of capillary leakage or serositis. No case of microcephaly, Guillain-Barre Syndrome (GBS) or morbidity associated with ZIKV infection was noted in this outbreak. The most affected age group was $21-30$ years (37.3\%) followed by 31-40 (29.9\%). Age and gender depiction of Zika confirmed cases are given Figure 5 .

A study has been initiated to find out the association between Blood groups and Zika positive cases showed that most of the ZIKV infected individuals were O+ve blood group (41.1\%) followed by B+ve blood group (33.9\%), A+ve blood group (17.9\%), B-ve blood group (3.5\%), AB+ve blood group (1.8\%) and O-ve blood group (1.8\%).

Among the $68 \mathrm{ZIKV}$ positive cases, 7 (10.29\%) were pregnant women. The first laboratory confirmed ZIKV case (24 year old native of Parassala, Thiruvananthapuram) delivered a 
healthy child and the condition of mother and child is stable.

\section{Vector Control Measures to Control ZIKV Transmission}

Approximately nine wards around the private hospital are considered as highly vulnerable for the disease transmission as a cluster of infection was identified in these areas. Hence a micro level containment program was prepared by the Thiruvananthapuram District health authorities in consultation with state health authorities and Central Disease Investigation Team (CDIT). As dengue and Chikungunya are reporting from most of the districts, a detailed action plan for vector control activities have been prepared so that the same will be helpful to avert the impending outbreak of Zika and other mosquito- borne diseases. Source reduction activities and environment management activities were done with the support and co-operation of the community and other governmental and non-governmental organizations. Subsequently, the disease was under control on the second week of August 2021.

\section{Discussion}

Zika virus (ZIKV) is a mosquito-borne zoonotic Flavivirus. ZIKV was considered to cause a mild febrile illness till the first documented outbreak occurred in 2007 in Yap Island in the Federated States of Micronesia. Due to the comparatively benign nature of the virus, the outbreak went calm without much fear or trepidation. However in the subsequent outbreaks, human ZIKV infection appears to have changed its characteristic clinical presentation. ${ }^{17}$ The first human case of ZIKV was confirmed in 1952. Thereafter, sporadic cases were reported in Africa and Asia for about 60 years. Within this period, the benign and mild Zika fever was turned into complex clinical presentations. Notably, during the last 15 years, ZIKV outbreak is associated with microcephaly and other neurological disorders, creating serious public health implications globally. ${ }^{18}$ Recent reports indicate that ZIKV could be sexually transmitted occurring from symptomatic and asymptomatic males and females ${ }^{11}$, which will increase the epidemic vulnerability and potentiality in various geographic areas.

India had experienced outbreaks of ZIKV disease in Gujarat, Tamil Nadu, Rajasthan and Madhya Pradesh during 2016-2018. ${ }^{19,20}$ However the earliest evidence of ZIKV dissemination in India was confirmed in 1954 by the then Virus Research Centre-VRC (ICMR-National Institute of Virology), Pune during its active surveillance to identify the viruses of public health importance in India. The samples collected from Bharuch and Kathiawar districts of Gujarat and Nagpur districts of Maharashtra had been tested positive for ZIKV. However, due to high cross reactivity of ZIKV with dengue virus (DENV) and other flaviviruses, it was difficult to confirm ZIKV infection based on serological study alone. These Zika positive cases did not have any travel history to ZIKV endemic region. This suggests that ZIKV is not recently set foot in our country and the virus may have been survived in the most suitable habitats and established its dominion very silently in various geographical regions. When the conditions become favorable, disease outbreaks may occur.

During the routine Entomological surveillance in Thiruvananthapuram district in April 2021, the team could notice several cases of dengue and Chikungunya from different areas of the district mostly from Thiruvananthapuram Corporation area. Some of the Medical officers residing in the city limits could also observe that some of their patients suffered from fever, head ache, itchy rashes which resolve itself within 4-5 days with symptomatic treatment. The District NVBDCP team could notice such cases in urban areas during the routine field visit in the month of May 2021 and informed the district health officials on the prevailing field situation. Amidst COVID-19 pandemic, dengue and Chikungunya cases were also on the rise in urban areas.

In this context, it is worthwhile to note that a multispecialty private hospital situated in Anamugham (Division No. 95) of Thiruvananthapuram Corporation area had sent 19 samples to NIV, Pune in May 2021 requesting to test for measles, rubella, dengue and Chikungunya. The head of the Infectious Disease Department (IDD) of the hospital suspected any of the aforesaid diseases as symptoms of the patients (working staff of the hospital- nurses, patient care assistant, nurse manager, pharmacist, food and beverage staff, general duty staff, etc.) are more or less same (fever, rashes, conjunctivitis, etc.). Meanwhile, a 24 year old woman, who had been in her final stage of gestation, got admitted for delivery in the same hospital on 28th June 2021 (She has been visiting the Gynecology department of the hospital for regular checkup). As she was suffering from fever, rashes and conjunctivitis immediately referred to IDD. There they tested for dengue and Chikunguniya, two most prevalent Aedes-borne diseases in Kerala and elsewhere, but both turned negative. As 19 samples sent to NIV, Pune in May 2021, have been tested negative for measles, rubella, dengue and Chikungunya, the sample of the pregnant woman was sent to the Microbiology laboratory at Coimbatore, Tamil Nadu on 4th July 2021 and asked them to look into the possibility of Zika virus (ZIKV). The sample has been tested positive for ZIKV. For confirmation, the sample was sent to NIV, Pune and confirmed as ZIKV positive on 8th July 2021. This is the first laboratory confirmed Zika virus in Kerala.

Earlier when they sent the samples to NIV, Pune did not suspect the Zika virus infection as this disease was not reported so far from Kerala. As one of the patient with 
similar symptoms turned ZIKV positive, the concerned Medical officer of the hospital requested NIV, Pune to test the samples (if present) to find out the possibility of Zika virus in those 19 samples sent earlier. The sample was adequate and hence NIV, Pune could test all the samples for Zika positivity. Among the samples (date of onset of the disease: 15th-21st May 2021), 14 samples were found positive for Zika. Thus it is exceedingly possible that the virus may already be in circulation in Kerala very silently without leading into outbreaks. There was no noticeable report of any abnormal developmental issues in newborn in anywhere in Kerala, especially in Thiruvananthapuram, where currently the virus is in circulation. Hence the present transmission of ZIKV is assumed to be of recent or is of very mild/ silent.

When any vector-borne disease outbreak occurs in a locality, especially of a new virus like Zika, the possibilities of the entry of the pathogen and its transmission potential is a matter of great concern and discussion. During the first reported outbreak of ZIKV in Kerala, particularly in the state capital, it is evident that none of the cases and their contacts had history of travel abroad or to other states of the country. For the sake of discussion, perhaps one can argue that the indigenous circulation of the virus and the presence of vector mosquitoes may lead to the emergence of ZIKV in Kerala. But this is a broad presumption and need sharp observations regarding the outbreak. In the very beginning, a cluster of ZIKV cases reported in a multispecialty hospital situated in Division No. 95 of Thiruvananthapuram Corporation area. The detection of ZIKV from Ae. aegypti mosquitoes collected from the discarded tires seen in the same hospital premise add the significance of this hospital/premise in the initiation of the present ZIKV outbreak. Further investigation revealed that during the months of April-May 2021, patients from 18 countries visited the same hospital for treatment. The details of the countries in relation to the present status of ZIKV transmission/vector prevalence ${ }^{21}$ is given in Table 4.

Table 4.Countries from Where the Patients Visited the Multispecialty Hospital during April-May 202 I and the Status of those Countries with Regard to ZIKV Transmission

\begin{tabular}{|c|c|c|}
\hline $\begin{array}{c}\text { S. } \\
\text { No. }\end{array}$ & Countries & $\begin{array}{c}\text { Present status of ZIKV } \\
\text { transmission/ vector prevalence }\end{array}$ \\
\hline 1. & Afghanistan & No mosquitoes that spread Zika \\
\hline 2. & Belgium & No mosquitoes that spread Zika \\
\hline 3. & Canada & No mosquitoes that spread Zika \\
\hline 4. & England & No mosquitoes that spread Zika \\
\hline 5. & Kuwait & $\begin{array}{c}\text { With Mosquitoes but no reported } \\
\text { Zika cases }\end{array}$ \\
\hline
\end{tabular}

\begin{tabular}{|c|c|c|}
\hline 6. & Oman & $\begin{array}{l}\text { With Mosquitoes but no reported } \\
\text { Zika cases }\end{array}$ \\
\hline 7. & Russia & $\begin{array}{l}\text { With Mosquitoes but no reported } \\
\text { Zika cases }\end{array}$ \\
\hline 8. & Switzerland & No mosquitoes that spread Zika \\
\hline 9. & Ukraine & No mosquitoes that spread Zika \\
\hline 10. & $\begin{array}{l}\text { South } \\
\text { Africa }\end{array}$ & $\begin{array}{l}\text { With Mosquitoes but no reported } \\
\text { Zika cases }\end{array}$ \\
\hline 11. & $\begin{array}{l}\text { United } \\
\text { states }\end{array}$ & $\begin{array}{l}\text { Current/past transmission but no } \\
\text { Zika outbreak }\end{array}$ \\
\hline 12. & Croatia & No mosquitoes that spread Zika \\
\hline 13. & Germany & No mosquitoes that spread Zika \\
\hline 14. & Italy & No mosquitoes that spread Zika \\
\hline 15. & Bangladesh & $\begin{array}{c}\text { First case of ZIKV infection reported } \\
\text { in August 2014. Unavailability of } \\
\text { diagnostic facility, lack of proper } \\
\text { surveillance, silent transmission of } \\
\text { ZIKV }\end{array}$ \\
\hline 16. & France & No mosquitoes that spread Zika \\
\hline 17. & $\begin{array}{l}\text { Saudi } \\
\text { Arabia }\end{array}$ & $\begin{array}{l}\text { With Mosquitoes but no reported } \\
\text { Zika cases }\end{array}$ \\
\hline 18. & Austria & No mosquitoes that spread Zika \\
\hline
\end{tabular}

Many patients from the abovementioned countries have reached in the same hospital for treatment during the early part of 2021 and most of them were from Zika unaffected areas. It is learnt that three women patients from Bangladesh admitted in the multispecialty hospital in May 2021. ZIKV was first confirmed in Bangladesh in 2014. Due to lack of test facilities, proper awareness among the physicians, Proper surveillance activities, no serological evidence is available among Bangladeshi population on ZIKV. The information on ZIKV available so far from Bangladesh is only tip of the ice berg. ${ }^{22}$ It is logical to consider that the virus is silently spreading in this country. ZIKV cases are not reporting or under-reporting in Southeastern countries including Bangladesh. It is significant in this context to note that the onset of clinical manifestations of Zika started in one of the staff of the same hospital on 15th May 2021. Though the hospital had sent 19 samples from the same hospital to NIV, Pune in the same month, they did not look for ZIKV infection and hence no report appeared on this virus infection. However $73 \%$ of the samples sent earlier at NIV, Pune turned Zika positive and all of them were working in the same hospital including the first ZIKV confirmed 24 year old pregnant woman.

The phylogenetic analysis indicated that the Bangladeshi strain belonging to Asian lineage. ${ }^{22}$ During the ZIKV outbreak in Jaipur, Rajasthan, the virus strain was found to cluster 
with Asian lineage. The sequences of ZIKV during the 2018 outbreak were different from those from Gujarat in $2016 .{ }^{15}$ The phylogenetic analysis showed that Jaipur strain belonging to Asian lineage is circulating on the ongoing ZIKV outbreak in Kerala. These sequences are excogitated to be evolved from a common ancestor that has advanced through Malaysia-Thailand-Indonesia route. Bangladesh is a densely populated country with rapid urbanization which might be a risk factor for ZIKV. ${ }^{23}$ Currently there is no effective epidemiological and entomological surveillance on ZIKV infections in Bangladesh. ZIKV is either circulating or remained as undiagnosed. ${ }^{24}$ The possibility of recent outbreak of ZIKV coupled with Bangladesh patients treated in the multispecialty hospital situated in Thiruvananthapuram cannot be ruled out. Majority of cases (85.5\%) have been reported from areas within $3 \mathrm{~km}$ radius of the hospital ward. Another significant point is ZIKV could be detected from the Ae. aegypti mosquitoes collected from the construction sites of the hospital premise. ZIKV detection from Ae. albopictus and $A$. vittatus mosquitoes collected from nearby divisions substantiate that our contention of disease outbreak in relation to the hospital/ premise is true.

Around the multispecialty hospital the construction work is progressing and most of the labors engaged for this are from other states such as Rajasthan, Madhya Pradesh, West Bengal etc. Most of the West Bengal labors are from Bangladesh. During the present outbreak, ZIKV was confirmed in one of the West Bengal labor. The labor colonies are also nearby. The recent outbreak of Zika in Kerala is associated with the entry of people from Zika affected areas, Vector abundance, and the virus detection from all the three species of Aedes mosquitoes in the ZIKV affected areas.

The detection of ZIKV from the adult Ae. aegypti, Ae. albopictus and $A e$. vittatus mosquitoes reared from immature mosquitoes and that too from the male and unfed mosquitoes from the affected areas indicate transovarial transmission of ZIKV. Therefore, regular vector surveillance and Integrated Vector Management (IVM) should be practiced to avoid impending outbreaks of this disease.

The entomological surveillance in the micro containment zones of ZIKV affected areas indicate that all the three Aedes larval indices were above the critical level in all the area surveyed. The observation on breeding preference of Aedes mosquitoes showed that the most preferred breeding sites were water stagnated areas in cemented floor of the newly constructed buildings followed by cement tanks/cement pits/grinding stone, discarded tires, etc. The vector surveillance during the first ZIKV outbreak in Jaipur, Rajasthan showed highest positivity of Aedes breeding in cemented tanks in the house premises. ${ }^{25}$

Analysis on age and gender profile of ZIKV confirmed patients indicated that females are more affected (66.2\%) than males (33.8\%) and the most affected age group is $21-30(37.3 \%)$ followed by $31-40$ (29.9\%). This is probably related to the occupation of the infected individuals. Majority of the Zika positive cases were health workers (52.9\%) followed by homemakers (18\%). Of the total Zika positive cases, 7 (10.3\%) were pregnant women.

In the present study, we observed that $89 \%$ of the Zika positive cases had rash followed by fever (78.1\%), conjunctivitis (51.6\%), body pain (50.0\%), joint pain $(37.5 \%)$, itching (23.4\%), etc. However the clinic-epidemiological study during the first ZIKV outbreak in Jaipur, Rajasthan showed only $21 \%$ of the Zika positive cases had conjunctivitis and rash in $16 \%$ of the cases only. Itching was not reported in their observation. ${ }^{26}$ This is in contrast with our observations. The duration of the illness lasts for an average 2.9 days. In $82.2 \%$ of Zika positive cases the duration of the illness lasts only $2-3$ days; however in $4.18 \%$ of cases the illness duration was 5-7 days.

It is observed that most of the ZIKV infective individuals are O+ve blood group. This is possible because the Ae. aegypti and $A$ e. albopictus mosquitoes have a predilection to land and bite on individuals with O+ve blood group. ${ }^{27,28}$

Among the 7 Zika infected pregnant women, one gave birth to a healthy child. Three of them got aborted due to fear of complications in newborn. The others are still in gestation period. However no case of mocrocephaly, Guillain-Barre syndrome, neurological complications or morbidity associated with ZIKV infection was identified in Thiruvananthapuram. Most of the positive cases showed mild symptoms and there was no mortality reported. The current ZIKV outbreak in Kerala could be controlled in time with timely vector surveillance and vector control activities by district and state health authorities (entomology and epidemiology teams) with the support and coordination of Director of Health Services (DHS), Ministry of Health and Family welfare, Government of Kerala. The service extended by National Centre for Disease Control (NCDC), Kerala, National Vector Borne Disease Control Program (NVBDCP), Delhi, Regional Health Office, Thiruvananthapuram, National Institute of Virology (NIV), Pune, Vector Control Research Centre (VCRC), Kottayam field unit, Rajiv Gandhi Center for Biotechnology (RGCB), Thiruvananthapuram, helped to control the disease outbreak. The advice and suggestions of Central Zika Investigation Team (CZIT) and overall supervision and monitoring of Ministry of Health, Government of Kerala could bring the disease under control within one month.

\section{Conclusion}

The emergence of Zika in Gujarat, Tamil Nadu, Rajasthan, Madhya Pradesh, Kerala and Maharashtra created a 
panic situation in the public health system of India. India is progressing its role as geographically emblematic for the ZIKV surveillance in different parts of the country. In this context it is necessary to screen all the new borne for microcephaly/neurological complications. A medical team should be constitute to look in to this aspect. It is imperious to resume human, veterinary, entomological and environmental surveillance to decide the incidence and geographic distribution of Zika virus, host and Vector. An elaborate surveillance with the active participation of public health authorities at local and regional level is needed in fighting and controlling spread of vector-borne diseases.

\section{Acknowledgements}

We thank all the technical staff of District and State Entomology Unit for their relentless work in Vector surveillance and Vector control operations. We also thank the health staff of Thiruvananthapuram Corporation for their service in source reduction activities in the whole urban area.

\section{Conflict of Interest: None}

\section{References}

1. Dick GW. Zika virus. II. Pathogenicity and physical properties. Trans R Soc Trop Med Hyg. 1952 Sep;46(5):521-34. [PubMed] [Google Scholar]

2. Dick GW, Kitchen SF, Haddow AJ. Zika virus. I. Isolations and serological specificity. Trans R Soc Trop Med Hyg. 1952 Sep;46(5):509-20. [PubMed] [Google Scholar]

3. Smithburn KC. Neutralizing antibodies against certain recently isolated viruses in the sera of human beings residing in East Africa. J Immunol. 1952 Aug;69(2):22334. [PubMed] [Google Scholar]

4. MacNamura FN. Zika virus: a report on three cases of human infection during an epidemic of jaundice in Nigeria. Trans R Soc Trop Med Hyg. 1954 Mar;48(2):13945. [PubMed] [Google Scholar]

5. Moore DL, Causey OR, Carey DE., Reddy S, Cooke AR, Akinkugbe FM, David-West TS, Kemp GE. Arthropodborne viral infections of man in Nigeria, 1964-1970. Ann Trop Med Parasitol. 1975 Mar;69(1):49-64. [PubMed] [Google Scholar]

6. Duffy MR, Chen TH., Hancock WT, Powers AM, Kool JL, Lanciotti RS, Pretrik M, Marfel M, Holzbauer S, Dubray C, Guillaumot L, Griggs A, Bel M, Lambret AJ, Laven J, Kosoy O, Panella A, Biggerstaff BJ, Fischer M, Hayes EB. Zika virus outbreak on Yap Island, Federated States of Micronesia. N Engl J Med. 2009 Jun;360(24):2536-43. [PubMed] [Google Scholar]

7. Patterson J, Sammon M, Garg M. Dengue, Zika and Chikunguniya: emerging arboviruses in the new world. West J Emerg Med. 2016 Nov;17(6):671-9. [PubMed] [Google Scholar]
8. Lanciotti RS, Kosoy OL, Laven J J, Velez JO, Lambert AJ., Johnson AJ, Stanfield SM, Duffy MR. Genetic and serologic properties of Zika virus associated with an epidemic, Yap State, Micronesia, 2007. Emerg Infect Dis. 2008 Aug;14(8):1232-9. [PubMed] [Google Scholar]

9. Campos GS, Banderia AC, Sardi SI. Zika virus outbreak, Bahia, Brazil. Emerg Infect Dis. 2015 Oct;21(10):1885-6. [PubMed] [Google Scholar]

10. Cao-Lormeau VM, Roche C, Teissier A, Robin E, Berry AL, Mallet HP, Sall AA, Musso D. Zika virus, French Polynesia, South pacific, 2013. Emerg Infect Dis. 2014 Jun;20(6):1085-6. [PubMed] [Google Scholar]

11. Musso D, Roche C, Robin E, Nhan T, Teissier A, Cao-Lormeau VM. Potential sexual transmission of Zika virus. Emerg Infect Dis. 2015 Feb;21(2):359-61. [PubMed] [Google Scholar]

12. Heukelbach J, Alencar CH, Kelvin AA, de Oliveira WK, Pamplona de Goes Cavalcanti L. Zika virus outbreak in Brazil. J Infect Dev Ctries. 2016 Feb;10(2):116-20. [PubMed] [Google Scholar]

13. Cardoso CW, Paploski IA, Kikuti M, Rodrigues MS, Silva MM, Campos GS, Sardi SI, Kitron U, Reis MG, Ribeiro GS. Outbreak of Exanthematous illness associated with Zika, Chikungunya and dengue Viruses, Salvador, Brazil. Emerg Infect Dis. 2015 Dec;21(12):2274-6. [PubMed] [Google Scholar]

14. Musso D. Zika virus transmission from French Polynesia to Brazil. Emerg Infect Dis. 2015 Oct;21(10):1887. [PubMed] [Google Scholar]

15. Sapkal GN, Yadav PD, Vegad MM, Viswanathan R, Gupta $\mathrm{N}$, Mourya DT. First laboratory confirmation on the existence of Zika virus disease in India. J Infect. 2018 Mar;76(3):314-7. [PubMed] [Google Scholar]

16. Gupta N, Yadav PD, Patil DY, Sapkal G. Preparedness of public health-care system for Zika virus outbreak: An Indian perspective. J Infect Public Health. 2020 Jul;13(7):949-55. [PubMed] [Google Scholar]

17. Cao-Lormeau VM, Musso D. Emerging arboviruses in the Pacific. Lancet 2014 Nov; 384(9954):1571-2. [PubMed] [Google Scholar]

18. de Araújo TVB, Rodrigues LC, de Alencar Ximenes RA, de Barros Miranda-Filho D, Montarroyos UR, de Melo $A P L$, Valongueiro $S$, de Albuquerque MFPM, Souza WV, Braga C, Filho SPB, Cordeiro MT, Vazquez E, Di Cavalcanti Souza Cruz D, Henriques CMP, Bezerra LCA, da Silva Castanha PM, Dhalia R, Marques-Júnior ETA, Martelli $\mathrm{CMT}$; investigators from the Microcephaly Epidemic Research Group; Brazilian Ministry of Health; Pan American Health Organization; Instituto de Medicina Integral Professor Fernando Figueira; State Health Department of Pernambuco. Association between Zika virus infection and microcephaly in Brazil, January to May, 2016: Preliminary report of a case-control study. 
Lancet Infect Dis. 2016 Dec;16(12):1356-63. [PubMed] [Google Scholar]

19. Bhardwaj S, Gokhale MD, Mourya DT. Zika virus: Current concerns in India. Indian J Med Res. 2017 Nov;146(5):572-5. [PubMed] [Google Scholar]

20. Gupta N, Kodan P, Baruah K, Soneja M, Biswas A. Zika virus in India : past present and future. QJM. 2019 Oct;hcz273. [PubMed] [Google Scholar]

21. Center for Disease Control (CDC). Traveler's health. National Centre for Emergency and Zoonotic Infectious Diseases (NCEZID), Division of Global migration and quarantine (DGMQ), May 24, 2021.

22. Muraduzzaman AKM, Sultana $S$, Shirin T, Khatun $S$, Islam MT, Rahman M. Introduction of Zika virus in Bangladesh: An impending public health threat. Asian Pac J Trop Med. 2017 Sep;10(9):925-8. [PubMed] [Google Scholar]

23. Streatfield PK, Karar ZA. Population changes for Bangladesh in the coming decades. J Health Popul Nutr. 2008;26(3):261-72. [PubMed] [Google Scholar]

24. Ali MY. Zika virus in Bangladesh. Faridpur Med. Coll. J. 2016;11(1):01. [Google Scholar]

25. Singh RK, Singh S. Prevalence of Aedes mosquitoes during the first outbreak of Zika in Jaipir City, India. J Commun Dis. 2019;51(3):33-9. [Google Scholar]

26. Malhotra B, Gupta V, Sharma P, Singh R, Sharma H, Vyas M, Mathur RP, Mathur VK, Meena D, Malhotra H, Yadav PD, Sapkal G, Pt U, Rao Deshpande G, Gunjikar $R$, Shaman H, Mourya DT, Gupta N, Singh S, Ravindran P, Tiwari J, Nyayanit DA, Kumar N, Phalke S, Chugani A, Bhandari S, Suravajhala P, Solanki PS, Salaria M. Clinico-epidemiological and genomic profile of firsy Zika Virus outbreak in India at Jaipur city of Rajasthan state. J Infect Public Health. 2020 Dec;13(12):1920-6. [PubMed] [Google Scholar]

27. Wood CS. ABO blood groups relation to selection of human hosts by yellow fever vector. Hum Biol. 1976 May;48(2):337-41. [PubMed] [Google Scholar]

28. Shirai Y, Funada H, Takizawa H, Seki T, Morohashi M, Kamimura K. Landing preference of Aedes albopictus (Diptera: Culicidae) on human skin among ABO blood groups, secretors or non-secretors, and $A B H$ antigens. J Med Entomol. 2004 Jul;41(4):796-9. [PubMed] [Google Scholar] 